\title{
Exhaustive semantic activation for reading ambiguous verbs in Chinese sentences
}

\author{
Chien-Jer Charles Lin ${ }^{1 *}$ and Yi-Rung Chen ${ }^{2}$
}

\author{
* Correspondence: \\ chiclin@indiana.edu \\ ${ }^{1}$ Department of East Asian \\ Languages and Cultures, Indiana \\ University, 355 North Jordan \\ Avenue, Bloomington, IN \\ 47405-1105, USA \\ Full list of author information is \\ available at the end of the article
}

\begin{abstract}
Studies of lexical ambiguity resolution in sentential contexts have not sufficiently considered the relatedness among an ambiguous word's meanings as a predicting factor for semantic activation. To better understand the relation between lexical access and discourse processing and the effect of semantic relatedness on lexical ambiguity resolution, a cross-modal lexical priming experiment focusing on Mandarin ambiguous verbs of varying degrees of semantic relatedness was conducted. The results indicated that both meanings of an ambiguous verb were activated regardless of contextual biases and the degrees of semantic relatedness between the associated meanings. Taken together with previous research, the present study suggests that the meanings of an ambiguous word (i.e., homophonic homographs, which share both phonological and orthographic representations) are co-activated exhaustively if they are syntactically licensed by the context. These results thus support the exhaustive semantic activation model of lexical ambiguity resolution and the syntax-first theory of sentence processing.

Keywords: Lexical ambiguity resolution, Homonymy, Polysemy, Semantic processing, Sentence processing, Logographic orthography, Syntax first, Modularity
\end{abstract}

\section{Background: lexical ambiguity resolution and modularity}

The human lexicon is known for having multiple mappings between forms and functions. The same lexical form is often associated with multiple meanings (e.g., bank referring to a financial bank and a riverbank), and different lexical forms may overlap in their semantic denotations (e.g., both buy and purchase referring to the action of acquiring by payment). This article focuses on the processing of the former type of lexical-semantic mapping in Chinese sentences, namely the resolution of lexical ambiguity during Chinese sentence comprehension.

Research on the processing of lexical ambiguity has produced robust evidence that ambiguous words are processed differently from unambiguous ones. One classic example of such an effect is the so-called number of meaning effect, according to which lexical forms associated with greater numbers of meanings are more quickly recognized than those associated with fewer or single meanings (Borowsky and Masson 1996; Hino and Lupker 1996; Hino et al. 2006; Jastrzembski 1981; Jastrzembski and Stanners 1975; Kellas et al. 1988; Lin and Ahrens 2010; Millis and Button 1989; Rubenstein et al. 1970, c.f., Rodd et al. 2002). A fundamental question that has recently regained much attention concerns 
the relation between lexical processing and how lexical ambiguity is defined (e.g., Klepousniotou and Baum 2007; Klepousniotou et al. 2012). While two words are both ambiguous, the types of ambiguity involved can be quite different. The meanings associated with date as shown in 1a, referring to 'a day', and 1b, referring to 'a fruit', for example, are relatively independent of each other while the meanings associated with film as shown in 2a, referring to 'the physical material used to produce motion pictures', and $2 \mathrm{~b}$, referring to 'a movie', are more closely related.

(1) a. She can't remember her father's date of birth.

b. Dried dates can be stored at room temperature.

(2) a. He shot a whole roll of film in one afternoon.

b. Ang Lee is a well-known film director.

In linguistic terms, the former type of ambiguity has been referred to as homonymy, the latter as polysemy (Allan 1986; Cruse 1986; Lyons 1995; Palmer 1981). Based on the derivative relation between meanings, those of a homonymous word are usually listed under separate lexical entries in a dictionary while those of a polysemous word are usually listed under the same lexical entry.

In the psycholinguistic literature, this homonymy/polysemy distinction has been operationalized using RELATEDNESS OF MEANING (henceforth, ROM) ratings, which are subjective ratings of how closely-related the meanings associated with a lexical form are (Azuma and Van Orden 1997; Durkin and Manning 1989). Homonyms like 1 tend to have lower ROM ratings; polysemes like 2 tend to have higher ROM ratings. The present study investigates how the meanings associated with an ambiguous word are accessed in sentential contexts, taking into consideration the relatedness among an ambiguous word's meanings. The target language of this investigation is Mandarin Chinese, whose logographic writing system presents a more direct relation between orthography and meaning than alphabetic languages (Hino et al. 2013; Zhou and Marslen-Wilson 2000).

How lexical ambiguity is resolved in sentences is of significant theoretical importance for sentence processing research as it sheds light on the relation between lexical processing and discourse processing. Theoretical controversies have been centered on when discourse information is used to selectively activate the contextually-supported lexical meanings. The MODULAR perspective for lexical and discourse processing maintains that the two processing systems are independent of each other (Fodor 1983; Forster 1979). Information inside the human lexicon is encapsulated and does not directly interact with discourse information at the initial stage of sentence processing. Under this view, the EXHAUSTIVE SEARCH MODEL (Ahrens 2001; Conrad 1974; Kintsch and Mross 1985; Lucas 1987; Onifer and Swinney 1981; Seidenberg et al. 1982; Swinney 1979; Swinney and Love 1996, among others) posits that (all) the meanings of an ambiguous word are automatically activated regardless of contextual support, the ORDERED ACCESS MODEL (Forster and Bednall 1976; Hogaboam and Perfetti 1975; Simpson and Burgess 1985) posits that, independent of context, lexical meanings are activated based on frequency rankings, with more frequent meanings accessed earlier than less frequent meanings. The INTERACTIVE MODEL on lexical and discourse 
processing, by contrast, posits that discourse information only facilitates the activation of the contextually-congruent meanings at an initial stage of lexical access (e.g., the SELECTIVE ACCESS MODEL of Glucksberg et al. 1986; Oden and Spira 1983; Paul et al. 1992; Simpson 1981; Simpson and Krueger 1991; Tabossi 1988; Tabossi et al. 1987; Vu et al. 1998, 2000; see also Marslen-Wilson and Tyler 1980; McClelland and Elman 1986).

Thus far, research has produced mixed results regarding the early contextual influence on lexical access. Supporting the modular view for lexical and discourse processing, a series of studies obtained quick activations of an ambiguous word's multiple meanings regardless of contextual biases at the initial stage and sustained activations of only the contextually supported meanings at a later stage (Ahrens 1998, 2001; Conrad 1974; Kintsch and Mross 1985; Lucas 1987; Onifer and Swinney 1981; Seidenberg et al. 1982; Swinney 1979; Swinney and Love 1996; Tanenhaus et al. 1979; Till et al. 1988). On the other hand, supporting the interactive theory, other studies reported that only the contextually supported meanings of an ambiguous word are activated throughout the whole process of lexical access (Glucksberg et al. 1986; Li 1998; Li and Yip 1996, 1998; Oden and Spira 1983; Paul et al. 1992; Simpson 1981; Simpson and Krueger 1991; Tabossi 1988; Tabossi et al. 1987; Vu et al. 1998, 2000). As will become clear in our review below, these mixed findings may have been due to the different types of lexical ambiguities adopted in different studies.

\section{Relatedness of meaning and processing ambiguous words in sentences}

Most psycholinguistic research on the ROM effects has so far focused on the distinction between homonymy and polysemy. For instance, polysemous words are recognized faster than homonymous words (Azuma and Van Orden 1997; Klepousniotou and Baum 2007; Locker et al. 2003; Rodd et al. 2002; for the magnetoencephalography methodology: Beretta et al. 2005; Pylkkänen et al. 2006). Words with high ROMs have thus been taken to involve more consistent mappings between lexical forms and meanings (Azuma and Van Orden 1997) and may have broader "attractor basins" (Rodd et al. 2002). However, the effect of ROM has also been challenged by Hino et al. (2006), who reported a null effect, and Hino et al. (2010), who argued that ROM is effective only at the post-lexical decision-making stage, not at the semantic coding stage of lexical access.

Alternatively, focusing on the relation between lexical access and discourse processing, the ROM effect has been investigated in semantically biased sentences. Take the ambiguous words presented in 1-2 as examples; researchers are interested in whether the 'fruit' meaning of the homonymous word date would be activated when it is presented in 1a and whether the 'content' meaning of the polysemous word film would be activated when it is presented in a sentential context like $2 \mathrm{a}$. This is the research question that the current study focuses on.

Several studies provided evidence for the effect of ROM, reporting different reading patterns on homonymous and polysemous words in contextually biased sentences (Frazier and Rayner 1990; Pickering and Frisson 2001; Williams 1992; cf., Klein and Murphy 2001, 2002). In terms of the duration of semantic 
co-activation, while the meanings of a homonymous are co-activated only briefly at the initial stage of lexical access (e.g., Tanenhaus et al. 1979), those of a polysemous word can remain active up to 850 milliseconds after the offset of the word (Williams 1992). In an eye-tracking study, Frazier and Rayner (1990) investigated sentences with homonymous nouns like the pitcher in 3 and sentences with polysemous nouns like the newspaper in 4, where 3a and $4 \mathrm{a}$ are the preferred (i.e., dominant) readings and $3 \mathrm{~b}$ and $4 \mathrm{~b}$ are the unpreferred (i.e., subordinate) readings.

(3) a. Of course the pitcher pleased Mary, being so elegantly designed.

b. Of course the pitcher pleased Mary, throwing so many curve balls.

(4) a. Unfortunately the newspaper was destroyed, lying in the rain.

b. Unfortunately the newspaper was destroyed, managing advertising so poorly.

For homonymous nouns but not polysemous nouns, eye fixations on the disambiguating regions of the subordinate meanings were longer than those on the dominant meanings. This finding suggested that the processor opts for the dominant meaning when it encounters a homonymous word but remains uncommitted to a particular meaning when it encounters a polysemous word. Pickering and Frisson (2001) found similar though delayed disambiguation patterns regarding the homonymy/polysemy distinction on English verbs. Regarding the effect of meaning relatedness, then, these findings suggested that the meanings of ambiguous words with higher ROMs are interconnected and tend to be co-activated. Note that since the disambiguating information in these studies appears a few words after the ambiguous words in these studies, the reading patterns most likely reflect differences at a later (i.e., postlexical) stage of lexical processing and therefore does not really speak directly to the modular vs. interactive debate, which focuses on the initial stage of lexical processing.

In a different condition, Frazier and Rayner (1990) placed the ambiguous words after disambiguating contexts as in 5-6; for both homonymous and polysemous words, shorter reading times were obtained on the dominant readings in $5 \mathrm{a}$ and $6 \mathrm{a}$ than on the subordinate readings in $5 \mathrm{~b}$ and $6 \mathrm{~b}$. These results suggested that, regardless of the preceding context, the processor is better prepared to access the dominant meanings of an ambiguous word. Even though Frazier and Rayner (1990) did not discuss their results in terms of the modular versus interactive relation between lexical access and discourse processing, their findings are more compatible with the ORDERED ACCESS MODEL under the modular view, according to which meanings associated with an ambiguous word are accessed in the order of frequency and independently of contextual congruity.

(5) a. Being so elegantly designed, the pitcher pleased Mary.

b. Throwing so many curve balls, the pitcher pleased Mary.

(6) a. Lying in the rain, the newspaper was destroyed.

b. Managing advertising so poorly, the newspaper was destroyed. 
To sum up, the relatedness among the meanings of an ambiguous word appears to be a relevant factor in resolving lexical ambiguity though it remains to be explored whether sentential contexts have an immediate effect on the activation of a particular meaning when the ROMs of the ambiguous words are contrasted.

Finally, it is worth noting that all of these previous studies on the homonymy/ polysemy distinction investigated languages that use alphabetic scripts like English (for a review, see Lupker 2007; n.b., Hino et al.'s 2010 study in Japanese). Whether similar ROM effects pertain to languages of a different orthographic typology remains to be better understood. Unlike alphabetic writing systems in which orthography represents sounds through which a word's meaning is accessed, the logographic orthography of a Chinese character is more directly associated with its meaning. In terms of the relation between orthography and meaning, therefore, the logographic script of Chinese provides a potentially more direct connection between form and meaning than alphabetic scripts, which has led researchers such as Hino et al. (2010) to hypothesizing that lexical decisions on words that are logographically-scripted (such as Chinese characters and Japanese Kanjis) may involve deeper semantic processing than words composed of alphabets (see also Zhou and Marslen-Wilson 2000, for evidence on quick semantic activations in recognizing logographically-scripted Chinese words) ${ }^{\mathrm{a}}$. Focusing on a logographicallyscripted language-Mandarin Chinese-in the current research thus allows us to re-examine the activation of word meanings using a writing system that is more likely to provide direct semantic access.

\section{Lexical ambiguity resolution in Chinese sentences}

Most research on lexical ambiguity resolution in reading Chinese sentences has adopted the cross-modal lexical decision paradigm, which we focus on in this section (for reviews of studies published in Chinese, see also Li et al. 2001; Guo et al. 2007, and Zhang et al. 2006). A sentence containing an ambiguous word is presented auditorily. When the ambiguous word in the sentence is reached, a target word appears on the computer screen for a lexical decision. If the time taken to recognize a visual target that is semantically related to the prime word is shorter than the time taken to recognize a visual word that is not semantically related, this meaning of the prime word is considered activated (Swinney 1979; Onifer and Swinney 1981). The timing desynchronization between the auditory prime word and the visual target word allows researchers to determine whether a meaning is active at a particular time point of lexical access.

Among studies that adopted the cross-modal lexical decision methodology in Mandarin Chinese, Ahrens $(1998,2001)$ reported activations of all meanings at the onset of an ambiguous prime, supporting the (MODULAR) EXHASUSTIVE ACCESS MODEL. Others (Li and Yip 1996; Shu et al. 舒华等 2000; Wu and Shu 武宁宁，舒华 2002; Zhou et al. 周治金等 2003) reported activation of only the contextually-appropriate meanings, supporting the (INTERACTIVE) SELECTIVE ACCESS MODEL. Factors such as the timing desynchronization between the prime and the target, ambiguity types, word lengths, and the syntactic categories of the ambiguous words, however, varied across studies. Table 1 compares these 
Table 1 Comparisons across studies adopting the cross-modal lexical priming paradigm for lexical ambiguity resolution in Mandarin Chinese

\begin{tabular}{|c|c|c|c|c|c|c|}
\hline Study & $\begin{array}{l}\text { Target timing } \\
\text { relative to the } \\
\text { prime }\end{array}$ & $\begin{array}{l}\text { Type of } \\
\text { ambiguity }\end{array}$ & $\begin{array}{l}\text { Word length } \\
\text { (morphological } \\
\text { complexity) }\end{array}$ & $\begin{array}{l}\text { Syntactic } \\
\text { category }\end{array}$ & Exemplar stimuli & $\begin{array}{l}\text { Contextual } \\
\text { effect }\end{array}$ \\
\hline \multirow{3}{*}{$\begin{array}{l}\text { Ahrens } \\
\text { (1998) }\end{array}$} & \multirow[t]{3}{*}{ Onset } & \multirow[t]{3}{*}{ Homograph } & \multirow[t]{3}{*}{ Di-morphemic } & \multirow[t]{3}{*}{ Nouns } & 機關 ji1guan1 & \multirow[t]{3}{*}{-} \\
\hline & & & & & 'institution' & \\
\hline & & & & & 'trap' & \\
\hline \multirow{3}{*}{$\begin{array}{l}\text { Ahrens } \\
\text { (2001) }\end{array}$} & \multirow[t]{3}{*}{ Onset } & \multirow[t]{3}{*}{ Homograph } & \multirow[t]{3}{*}{ Di-morphemic } & \multirow[t]{3}{*}{ Verbs } & 背書 bei4shu1 & \multirow[t]{3}{*}{-} \\
\hline & & & & & 'memorize' & \\
\hline & & & & & 'guarantee' & \\
\hline \multirow[t]{2}{*}{$\begin{array}{l}\text { Shu et al. } \\
\text { (2000) Exp. } 2\end{array}$} & $\begin{array}{l}150 \text { ms before } \\
\text { offset }\end{array}$ & \multirow[t]{2}{*}{ Homophone } & \multirow[t]{2}{*}{ Di-morphemic } & \multirow[t]{2}{*}{ Verbs } & $\begin{array}{l}\text { 發言 falyan2 'to } \\
\text { speak' }\end{array}$ & + \\
\hline & Offset & & & & $\begin{array}{l}\text { 發炎 falyan2 'to be } \\
\text { infected with } \\
\text { inflammation' }\end{array}$ & + \\
\hline \multirow{3}{*}{$\begin{array}{l}\text { Wu and Shu } \\
\text { (2002) }\end{array}$} & Onset & \multirow[t]{3}{*}{ Homograph } & \multirow[t]{3}{*}{ Monomorphemic } & \multirow{3}{*}{$\begin{array}{l}\text { Multiple } \\
\text { syntactic } \\
\text { categories }\end{array}$} & 花 hual & + \\
\hline & Before offset & & & & 'to spend' (verb) & + \\
\hline & Offset & & & & 'colorful' (adjective) & + \\
\hline \multirow[t]{2}{*}{$\begin{array}{l}\text { Zhou et al. } \\
\text { (2003) Exp. } 2\end{array}$} & $\begin{array}{l}150 \mathrm{~ms} \text { before } \\
\text { offset }\end{array}$ & \multirow[t]{2}{*}{ Homophone } & \multirow[t]{2}{*}{ Di-morphemic } & \multirow[t]{2}{*}{ Nouns } & $\begin{array}{l}\text { 保健 bao3jian4 } \\
\text { 'hygiene' }\end{array}$ & + \\
\hline & $\begin{array}{l}50 \text { ms after } \\
\text { offset }\end{array}$ & & & & $\begin{array}{l}\text { 宝剑 bao3jian4 } \\
\text { 'sword' }\end{array}$ & + \\
\hline
\end{tabular}

studies in terms of these various methodological factors ${ }^{\mathrm{b}}$. Even though the findings in these studies appear to be inconsistent, once we consider these methodological differences across different studies, a rather consistent picture about whether the context has an immediate influence on the access of word meanings starts to emerge.

First, focusing on the timing desynchronization between the auditory prime and the visual target, the visual targets have been presented at the onset of the auditory prime (Ahrens 1998, 2001; Wu and Shu 2002), 150 milliseconds before the offset of the auditory prime (Shu et al. 2000; Wu and Shu 2002; Zhou et al. 2003), or at/after the offset of the auditory prime (Wu and Shu 2002; Zhou et al. 2003). The same methodological variability can be found in the non-Mandarin studies. Some studies placed the target word at the acoustic onset of the ambiguous word (e.g., Ahrens 2006; Onifer and Swinney 1981; Seidenberg et al. 1982; Swinney 1979; Tabossi 1988; Tabossi et al. 1987; Vu et al. 1998, 2000), some between the onset and the offset (e.g., Li and Yip 1996, 1998; Tabossi and Zardon 1993; Till et al. 1988), and others after the offset position (e.g., Simpson 1981). The presentation time point of the visual target in relation to the ambiguous prime word is a critical determinant for semantic activation. Onifer and Swinney (1981), for instance, found exhaustive semantic access for the early test points but only selective access for the delayed presentation points. According to the meta-analysis performed by Lucas (1999) and Guo et al. (2007), studies where targets were presented at or later than the offset of the prime words were more likely to show the postlexical processes. While it is uncontroversial that at the offset of an ambiguous word the processor already settles on the contextually appropriate meaning, divergent findings have been reported regarding contextual 
influence during the early stage of lexical access (at the onset or before the offset). For semantic activations at the initial stage of lexical access, it has been suggested that the target word should be presented no later than the offset of the prime word (Tabossi and Zardon 1993; see also Ahrens 1998). In our review regarding the relation between lexical access and discourse processing, we therefore focus on the experimental conditions where a target word was presented at the onset (Ahrens 1998, 2001; Wu and Shu 2002) or between the onset and the offset (Shu et al. 2000; Wu and Shu 2002; Zhou et al. 2003) of the prime word.

Before moving on to other methodological differences, it should be noted here that even the presentation duration of the visual targets can modulate the contextual effects observed (Ahrens 1998, 2006). When the presentation duration was shorter than 1000 milliseconds (for example, 300 milliseconds in Ahrens 1998, and 300 and 750 milliseconds in Ahrens 2006), exhaustive access of ambiguous meanings has been observed. When the visual stimuli were presented for 1500 milliseconds (Ahrens 2006), selective access has been observed. This information, however, has rarely been provided in previous reports.

In terms of the types of lexical ambiguity investigated, as can be seen in Table 1, homographs and homophones have respectively been used as the experimental stimuli in different studies. The homonymy/polysemy distinction, which we discussed in the introduction, focuses on whether the meanings associated with a lexical form are semantically related. In defining what a "lexical form" is, one can rely on orthography, phonology, or both. If we reply on identical orthography, then the ambiguous words are called HOMOGRAPHS. Chinese HOMOGRAPHS are words that share logographic (and usually also phonological) representations ${ }^{\mathrm{c}}$. For example, the mono-morphemic logograph 機 $j i 1$ is associated with meanings such as 'opportunity' and 'device'. The dimorphemic compound verb 下台 xia4tai2 is composed of two logographs 下 xia4 'to descend' and 台 tai2 'stage'. Put together, the compound verb literally means 'to come off stage' and has been metaphorically extended to mean 'to resign from an official position'. In general, homographic meanings associated with di-morphemic disyllabic Mandarin words tend to have higher ROMs because the associated meanings usually hold derivative relations.

By contrast, if we rely on phonology in defining lexical forms, then ambiguous words, called HOMOPHONES, are words that happen to share the same phonology but may differ in orthography. For instance, the phonological representation ji1 is associated with logographs such as 機 ‘opportunity; device, 雞 'chicken', 積 'to accumulate', and 激 'to arouse' (among over 90 logographs that share this same phonological representation in Mandarin), each of which has at least one distinct core meaning. As a di-morphemic example, the phonological word dian4yuan 2 is associated with two distinct orthographic forms一電源 'electric power' and 店員 'shopkeeper'. In contrast to homographs, homophonic entries are usually accidentally associated and tend to have lower ROMs.

In reviewing the studies summarized in Table 1, this orthographic difference between homography and homophony corresponds with the availability of early contextual influence on lexical access. Studies that found quick activations of multiple meanings used di-morphemic homographs as the stimuli, which tend to have higher ROMs (Ahrens 1998, 2001) d $^{\text {. }}$ Studies that found selective semantic activation based on context used homophones that do not share orthography as their stimuli, which tend to have lower ROMs (Shu et al. 2000; Zhou et al. 2003; also the Cantonese study of Li and Yip 1996). Such a dichotomy suggests 
that whether the meanings of a lexical form are co-activated in Chinese may depend on whether they share the same logographic representations. Co-activation of meanings would be observed if the semantic entries share the same orthographic form, as is the case of a Chinese homograph. Selective activation of meanings based on context would be observed if the meanings share phonological representations but not logographic representations, as is the case of a Chinese homophone. Based on this generalization, we propose the ORTHOGRAPHY-BASED SEMANTIC CO-ACTIVATION CONSTRAINT:

\section{(7) ORTHOGRAPHY-BASED SEMANTIC CO-ACTIVATION CONSTRAINT:}

Only meanings associated with the same orthographic (logographic) representations can be co-activated in sentential contexts.

An alternative account for the dichotomy between homography and homophony is the ROM of an ambiguous word-given that the ROM of a homograph tends to be higher than that of a homophone. With regard to the effect of ROM, we propose to test the RELATEDNESS-TRIGGERED SEMANTIC CO-ACTIVATION HYPOTHESIS:

\section{(8) RELATEDNESS-TRIGGERED SEMANTIC CO-ACTIVATION HYPOTHESIS:}

Meanings associated with a lexical form (defined orthographically and/or phonologically) are co-activated when the semantic relatedness between them is high.

This hypothesis contrasts with the ORTHOGRAPHY-BASED SEMANTIC COACTIVATION CONSTRAINT in that it deems the semantic relatedness between associated meanings, not the shared orthography, as the determinant for semantic coactivation. This hypothesis predicts that when the ROM of an ambiguous word is high (as in a homograph), meanings tend to be co-activated. When the ROM is low (as in a homophone), meanings tend to be selectively activated based on the context.

Contrasting 7 with 8 has important typological implications for the role that logographic orthography plays in semantic activation. If the ROM effect correctly predicts the availability of semantic co-activation, then the semantic relatedness between the meanings of a lexical form may serve as a universal predictor for semantic co-activation. If, however, ROM does not predict semantic activation, then logographic representations serve as an additional constraint on semantic co-activation. Only meanings associated with the same logographic forms are co-activated, suggesting that a language with a logographic orthography like Chinese is sensitive to logographic representations for accessing semantic representations (see also Sproat 2000 and Huang and Xue 2015 on the role that the Chinese orthography plays in lexical processing). Meanings associated with the same sounds do not sufficiently lead to semantic co-activation.

In addition to the types of lexical ambiguities and the timing setups, Table 1 also shows that the syntactic categories associated with an ambiguous word may be relevant to the diverse findings. Among studies that used homographs as stimuli, Wu and Shu (2002) stood out as the only study that observed early contextual influence on semantic activation. Two important properties about Wu and Shu (2002) should be noted. First, their homographs are monosyllabic, which, unlike disyllabic homographs, tend to have lower relatedness among the associated meanings. Second, and more importantly, the homographs in their study were associated with distinct 
syntactic categories (e.g., the homograph 花 hual can be an action verb, 'to spend', and a stative verb, 'to be colorful').

This is reminiscent of the syntax-first theory of sentence comprehension (Ferreira and Clifton 1986; Frazier 1987; Frazier and Fodor 1978; Friederici 2002; McElree and Griffith 1998), according to which the sentence processor uses syntactic information in the context to make predictions about the syntactic properties of an upcoming word. Semantic integration is executed based on the syntactic categories suggested by the syntactic parser. We thus propose the SYNTACTICALLY LICENSED SEMANTIC CO-ACTIVATION CONSTRAINT, which posits that a particular meaning of an ambiguous word can only be activated when its associated syntactic category matches the category predicted by the syntactic parser (see also Friederici and Weissenborn 2007):

(9) SYNTACTICALLY LICENSED SEMANTIC CO-ACTIVATION CONSTRAINT:

Meanings associated with a lexical form (defined orthographically and/or

phonologically) can only be co-activated in a sentential context when the associated meanings bear the syntactic properties predicted by the syntactic parser.

Take the syntactically ambiguous homograph 花 hua1 as an example again. Before it appears in a sentence, the context already suggests the parse of an action verb in $10 \mathrm{a}$ and the parse of a stative verb in 10b respectively. Under the SYNTACTICALLY LICENSED SEMANTIC CO-ACTIVATION CONSTRAINT, the two meanings associated with 花 hua1 would be selectively activated depending on whether the context predicts an action verb or a stative verb.

(10) a. 她為了買這件裙子花了很多錢。

$$
\begin{aligned}
& \text { ta1_wei4_le0__mai3_zhe4_jian4_qun2zi0_hua1_le0_hen3duo1_qian2 } \\
& \text { she_for_ASP_buy_this_CL_skirt_spend_ASP_very-much_money }
\end{aligned}
$$

She spent a lot of money buying this skirt.

b. 她買的這件裙子太花了。

$$
\text { ta1_mai3_de0_zhe4__ian4_qun2zi0_tai4_hua1_le0 }
$$

The skirt she bought was too colorful (meaning it has too much color on it).

On the other hand, when the meanings associated with an ambiguous word are both syntactically licensed (e.g., being of the same syntactic category), they can be co-activated regardless of the semantic congruity with the context. As an example, the meanings associated with the homograph 裝 zhuang1 ('to pack' and 'to pretend' in 11a and 11b respectively), though being semantically independent of each other, may still be co-activated given both meanings are associated with the same predicted syntactic category (i.e., verb).

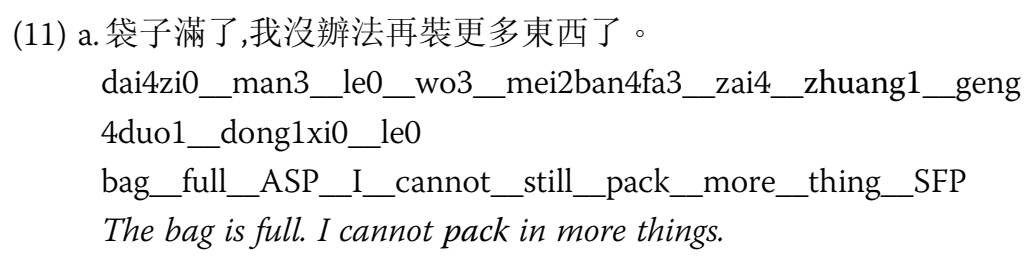




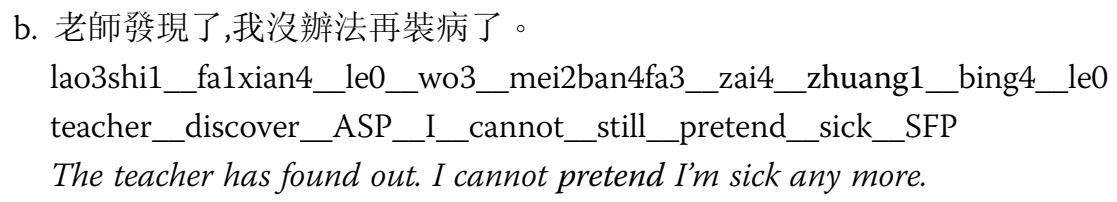

The present study focuses on the hypothesis sketched in 8 , taking into consideration both constraints summarized in 7 and 9 in the experimental design. A cross-modal lexical decision experiment was conducted. To make sure that any observed semantic activation took place during the early stage of lexical access, the visual targets were presented 100 milliseconds before the offsets of the ambiguous prime words (Ahrens 1998; Tabossi and Zardon 1993). To increase the possibility of semantic co-activation, the ambiguous prime words selected were all mono-morphemic homographs in Mandarin whose meanings share the same orthographic and phonological representations so that the ORTHOGRAPHY-BASED SEMANTIC CO-ACTIVATION CONSTRAINT can be satisfied. To satisfy the SYNTACTICALLY LICENSED SEMANTIC CO-ACTIVATION CONSTRAINT, the meanings associated with the ambiguous prime words were of the same syntactic categories (i.e., verbs), and therefore were syntactically licensed by the same sentential context regardless of semantic congruity. To avoid the complex morphological processes that may be involved in accessing disyllabic Chinese words, which tend to be compounded, and to better control for the presentational timing of the target words relative to the ambiguous primes, the present study only used monosyllabic verbs as the ambiguous prime stimuli.

\section{Research questions and predictions of the present study}

The purpose of the present study is to investigate whether the relation between lexical and discourse processing is modular or interactive and whether the relatedness of a word's meanings affects the activation of meanings in biased sentential contexts (i.e., the RELATEDNESS-TRIGGERED SEMANTIC CO-ACTIVATION HYPOTHESIS). We seek to answer the following two questions:

- Are the multiple meanings of an ambiguous word (i.e., homographs in the present study) activated at the initial stage of lexical processing? Does context have an immediate effect on the activation of an ambiguous word's meanings?

- Does the relatedness between an ambiguous word's meanings affect the activation of a particular meaning?

In the experiment reported below, sentential contexts are biased towards the primary (i.e., the more frequent) meanings of the ambiguous words. Activations of the primary meanings are therefore expected. Activation of the secondary meanings in these contexts, if any, can serve as evidence supporting the exhaustive activation theory of lexical access. The interactive theory, on the other hand, would be supported if a meaning that is semantically congruent with the context is the only meaning that is activated.

Among the selected ambiguous words, half were of high ROMs; half were of low ROMs. If the RELATEDNESS-TRIGGERED SEMANTIC CO-ACTIVATION 
HYPOTHESIS holds true, then ambiguous words with high ROMs and those with low ROMs should display distinct patterns of semantic activation: meanings that are closely related would be co-activated regardless of the contextual bias while meanings that are not closely-related would be selectively activated depending on the contextual support.

Taken together, we make the following predictions. If lexical processing is modular (i.e., independent of discourse processing), then we would expect all associated meanings to be activated regardless of contextual support and ROM. This finding will not support the RELATEDNESS-TRIGGERED SEMANTIC CO-ACTIVATION HYPOTHESIS. If lexical processing and discourse processing have an interactive relation, we would expect early contextual influence on semantic activation. Supporting the RELATEDNESSTRIGGERED SEMANTIC CO-ACTIVATION HYPOTHESIS, co-activations of multiple meanings would be observed on words of high ROMs while selective activations of only the contextually supported meanings would be observed on words of low ROMs. If, however, only the contextually supported meanings were activated for both words of high ROMs and words of low ROMs, then the RELATEDNESS-TRIGGERED SEMANTIC CO-ACTIVATION HYPOTHESIS is not supported.

\section{Method}

A cross-modal lexical decision experiment (Swinney 1979) was conducted. In each trial of this experiment, the participants were auditorily played a Mandarin Chinese sentence containing an ambiguous verb. At the time when the ambiguous word appeared, a visual target was presented on the computer screen 100 milliseconds before the offset of the ambiguous word for a lexical decision. The semantic relation between the visual target and the ambiguous prime verb was manipulated to investigate whether a particular meaning of an ambiguous verb was activated. If a particular meaning of the prime word is activated, it is expected that a visual target that is semantically related to this meaning should receive facilitation for word recognition.

\subsection{Pretests}

In order to control for various variables on the experimental materials, a series of pretests were conducted. For the auditory prime words, an initial list of 140 monosyllabic ambiguous verbs was first selected as candidates. To determine the primary and secondary meanings of each verb, meanings associated with each ambiguous word were listed in a meaning ranking questionnaire, which recruited 238 participants (109 males and 129 females, native speakers of Mandarin Chinese aged between 20-26, mean age $=23, S D=1.93)$ to provide meaning rankings associated with each word. Sixty-one words, whose primary meanings were rated as the first meanings by over $70 \%$ of the participants (mean dominance $=81.07 \%, S D=8.55 \%$ ), were selected as the candidate stimuli. The primary and secondary meanings of these 61 words were further paired in a semantic relatedness questionnaire, for which 62 participants (17 males and 45 females, aged between $19-26$ years old, mean age $=22.19, S D=2.54)$ rated relatedness of meaning using a 7 -point scale $(1=$ not related, $7=$ closely related $)$. Based on the semantic relatedness scores, experimental items were classified into those that have 
high ROMs (i.e., 24 words with an ROM over 4.5) and those that have low ROMs (i.e., 21 words with an ROM below 3.5).

To make sure that all words were familiar to participants, the 21 low-ROM words and 24 high-ROM words selected from the semantic relatedness questionnaire were subjected to familiarity ratings using a word familiarity questionnaire (40 participants-13 males and 27 females, aged between 19-25 years old, mean age $=22, S D=2.22$-rating word familiarity on a 7-point scale, 1 = not familiar, 7 = very familiar). Sentential contexts, which are biased toward the primary meanings, were created where these ambiguous words were embedded. To control for the strengths of contextual biases in the auditory sentences, a sentence completion task was conducted, in which 36 participants (16 males and 20 females, aged between 19-24, mean age $=20.6, S D=1.68$ ) completed sentences based on the sentence fragments. A sentence was accepted as an experimental item if at least $75 \%$ of participants completed the sentence fragment using the ambiguous word itself or its synonyms (Tabossi et al. 1987). The sentential materials were equated on the number of characters preceding the prime verb and the total length of the sentential contexts.

Visual targets associated with the auditory prime words were selected based on the definitions provided in Chinese Wordnet (Huang et al. 2010) and Ministry of Education Revised Chinese Dictionary (1994). All the visual probes are unambiguous words based on Ministry of Education Revised Chinese Dictionary (1994). For these visual targets, a prime-target semantic association questionnaire was conducted, in which 24 participants (7 males and 17 females, aged between 19-23, mean age $=21.05, S D=1.36$ ) rated the degree of semantic association between the prime and the target words on a sevenpoint scale $(1=$ not semantically associated, $7=$ highly semantically associated). A lexical decision experiment (20 participants, paid 100 New Taiwan Dollars, Mandarinspeaking undergraduate students at National Taiwan Normal University, 6 males and 14 females, aged between $18-22$, mean age $=20.45, S D=1.15$ ) was then conducted to ensure that the visual targets induced comparable response times when they are presented in isolation. All the pretests were completed by different native Mandarin Chinese speakers in Taiwan. Details about these pretests and the actual experimental stimuli are provided as Additional file 1 (pretest details, auditory prime words and visual targets, and sentential materials in which the prime words were embedded) at the first author's personal website (https://sites.google.com/site/chienjer/) and at Research Gate https://www.researchgate.net/profile/Chien-Jer_Lin.

\subsection{Participants}

Forty-eight native speakers of Mandarin Chinese (13 males, 35 females) aged 18-23 (mean age $=20.5, S D=1.7$ ) were paid to participate in the cross-modal lexical decision experiment. All participants learned only Mandarin and Taiwanese Southern Min and no other languages or dialects before the age of 7 . None of the participants took part in any of the pretests.

\subsection{Stimuli}

The materials included three sets of auditory prime words selected based on the pretests (i.e., 16 prime words with low ROMs, 16 prime words with high ROMs, and 16 unambiguous prime words) presented in sentential contexts that are biased toward the primary meanings of the ambiguous words. As exemplified by Table 2, four types of 
Table 2 Auditory primes 學 xue2, 裝 zhuang1, 喝 he1 and their visual targets

\begin{tabular}{|c|c|c|c|}
\hline \multirow[t]{2}{*}{ Auditory prime } & \multirow[t]{2}{*}{ Meanings } & \multicolumn{2}{|l|}{ Visual target } \\
\hline & & Experimental target & Control target \\
\hline \multirow{2}{*}{$\begin{array}{l}\text { 學 xue2 [ROM= } \\
5.52]\end{array}$} & Primary: 'to learn' & 研習 yan2xi2 'to study' & 創立 chuang4li4 'to establish' \\
\hline & $\begin{array}{l}\text { Secondary: 'to } \\
\text { imitate' }\end{array}$ & $\begin{array}{l}\text { 模仿 mo2fang3 'to } \\
\text { imitate' }\end{array}$ & 表明 biao3ming2 'to state clearly' \\
\hline \multirow[t]{2}{*}{$\begin{array}{l}\text { 裝 zhuang1 } \\
\text { [ROM = 1.71] }\end{array}$} & Primary: 'to pack into' & $\begin{array}{l}\text { 放進 fang } 4 j i n 4 \text { 'to put } \\
\text { into' }\end{array}$ & $\begin{array}{l}\text { 發炎 falyan2 'to be infected with } \\
\text { inflammation' }\end{array}$ \\
\hline & $\begin{array}{l}\text { Secondary: 'to } \\
\text { pretend' }\end{array}$ & $\begin{array}{l}\text { 假冒 jia3mao4 'to } \\
\text { pretend' }\end{array}$ & 警示 jing3shi4 'to warn' \\
\hline 喝 hel & $\begin{array}{l}\text { 'to drink' } \\
\text { (unambiguous) }\end{array}$ & $\begin{array}{l}\text { 飲用 yin3yong4 'to } \\
\text { drink' }\end{array}$ & 指派 zhi3pai4 'to appoint' \\
\hline
\end{tabular}

visual targets were created for each auditory prime, including (i) a semantic associate of the primary meaning, (ii) a semantic associate of the secondary meaning, (iii) a semantically unrelated control word matched with the semantic associate of the primary meaning, and (iv) a semantically unrelated control word matched with the semantic associate of the secondary meaning. In addition to the ambiguous primes, an additional condition made of unambiguous verbs was included as the control condition.

The auditory prime words were embedded in 48 sentences (recorded by a female Mandarin speaker from Taiwan), which were biased towards the primary meanings of the ambiguous words. Examples of the auditory sentences containing ambiguous primes are given in 12 and 13 for the high-ROM verb 學 xue $2(\mathrm{ROM}=5.52)$ 'to learn, to imitate' and the low-ROM verb 裝 zhuang1 ( $\mathrm{ROM}=1.71$ ) 'to pack, to pretend' respectively. The ambiguous words are in bold face.

(12) 為了提升孩子的競爭力,許多家長都會帶小朋友去才藝班學各種技能,卻完全 沒有考慮到小孩子的感受。

wei4_le0_ti2sheng1_hai2zi0_de0_jing4zheng1li4,_xu3duo1_jia1

zhang3_dou1_hui4_dai4_xiao3peng2you3_qu4_cai2yi4ban1

xue2_ge4_zhong3_ji4neng2,_que4_wan2quan2_mei2you3_

kao3lyu4dao4_xiao3hai2zi0_de0_gan3shou4

for_ASP_enhance_child_DE_competitiveness,_many_parents_

all_will_take_children_go_talent-classes_learn_every_kind_skill,_

but_completely_not_consider_child_DE_feeling

In order to make their children more competitive, many parents send their

kids to talent classes to learn all kinds of skills without considering how their children feel about it.

（13）阿民特地去賣場買了一個大背包,這樣就能把所有的登山用具通通裝到裡

面,活動起來也比較方便。

a1ming2_te4di4_qu4_mai4chang3_mai3_le0_yi2_ge0_da4_bei1bao1, zhe4yang4_jiu4_neng2_ba3_suo3you3__de0_deng1shan1_yong4ju4_-

tong1tong1_zhuang1dao4__li3mian4,_huo2dong4qi3lai2_ye3_bi3jiao4_

fang1bian4 
A-Ming_purposefully_go_store_buy_ASP_one_CL_big_backpack, this-way_then_can_BA_all_DE_mountain-climbing_tool_all_pack_ inside,_move_also_more_convenient

A-Ming went to the store to buy a big backpack so that he could pack all the tools for mountain climbing into it and be more mobile while doing activities.

The characteristics of the prime words and the visual targets are summarized in Tables 3 and 4 respectively. These experimental trials were then assigned to experimental lists following a Latin Square Design. Non-words, which appeared in half of the 48 trials, were made of pseudohomophones, i.e., nonexistent words composed of Chinese characters that have the same sounds as real words. As an example, the pseudohomophone 疑凍 yi2dong4 is composed of two Chinese characters 疑 yi2 'to question' and 凍 dong4 'to freeze', which are homophonic to the characters of an existing verb 移動 yi2dong4 'to move'.

\subsection{Procedure}

Participants were tested individually in the Language and Cognition Laboratory of the first author. After filling out an information sheet about linguistic backgrounds, they were seated in front of a computer monitor and instructed to carefully listen to sentences through headphones in order to identify the auditory sentences at the end of each of the two blocks of the experiment. For the lexical decision tasks, participants needed to decide if two visually presented Chinese characters that appeared on the computer monitor composed existing words in Chinese. Following Tabossi and Zardon (1993), who suggested 100 milliseconds before the offset as an appropriate time point that is late enough so that semantic activation can be initiated but early enough so that

Table 3 Stimulus characteristics of the auditory primes

\begin{tabular}{lccc}
\hline & Prime groups & & \\
\cline { 2 - 4 } & Low-ROM verbs & High-ROM verbs & Unambiguous verbs \\
\hline Word frequency & 603.56 & 729.75 & 477.88 \\
Syllable length & 1.00 & 1.00 & 1.00 \\
Homophone dominance (\%) & 61.79 & 64.29 & 60.51 \\
Number of meanings & 4.69 & 4.56 & 1.00 \\
Number of syntactic categories & 1.88 & 1.69 & 1.44 \\
Percent of verb usage & 98.91 & 98.38 & 97.03 \\
Number of arguments & 2.13 & 2.06 & 2.06 \\
Relatedness of Meaning (1-7) & 2.47 & 5.08 & $\mathrm{n} / \mathrm{a}$ \\
Familiarity rating (1-7) & 6.83 & 6.8 & $\mathrm{n} / \mathrm{a}$ \\
Percent of primary meaning & 82.38 & 79.75 & $\mathrm{n} / \mathrm{a}$ \\
Percent of secondary meaning & 56.56 & 60.69 & $\mathrm{n} / \mathrm{a}$ \\
\hline
\end{tabular}

Note. Homophone dominance $=$ frequency of the stimulus relative to the overall syllable frequency calculated based on the Academia Sinica Balanced Corpus of Modern Chinese 4.0 (Chen et al. 1996); number of syntactic categories = number of different syntactic categories associated with the stimuli based on Chinese Wordnet (Huang et al. 2010) and Ministry of Education Revised Chinese Dictionary (1994); percent of verb usage = relative frequency of the prime word used as a verb in Academia Sinica Balanced Corpus of Modern Chinese 4.0; number of arguments = number of obligatory arguments for the primary meaning of each verb; percent of primary meaning = percentage of participants that rated the primary meaning as the primary meaning; percent of secondary meaning = percentage of participants that rated the secondary meaning as the secondary meaning 
Table 4 Stimulus characteristics of the visual target words

\begin{tabular}{|c|c|c|c|c|c|c|c|c|c|c|}
\hline \multirow{4}{*}{$\begin{array}{l}\text { Prime types } \\
\text { Meaning } \\
\text { Experimental/Control }\end{array}$} & \multicolumn{10}{|c|}{ Target groups } \\
\hline & \multicolumn{4}{|c|}{ Low-ROM verbs } & \multicolumn{4}{|c|}{ High-ROM verbs } & \multirow{2}{*}{\multicolumn{2}{|c|}{$\begin{array}{l}\text { Unambiguous } \\
\text { verbs }\end{array}$}} \\
\hline & \multicolumn{2}{|l|}{ Primary } & \multicolumn{2}{|c|}{ Secondary } & \multicolumn{2}{|l|}{ Primary } & \multicolumn{2}{|c|}{ Secondary } & & \\
\hline & Exp & Control & Exp & Control & Exp & Control & Exp & Control & Exp & Control \\
\hline Word frequency & 90.63 & 86.94 & 68.25 & 67.38 & 131.13 & 133.13 & 108.31 & 105.75 & 139.38 & 133.94 \\
\hline $\begin{array}{l}1^{\text {st }} \text { character } \\
\text { frequency }\end{array}$ & 405.31 & 451.81 & 709.88 & 1424.06 & 765.31 & 1141.56 & 364.31 & 155.38 & 600.00 & 494.56 \\
\hline $\begin{array}{l}2^{\text {nd }} \text { character } \\
\text { frequency }\end{array}$ & 581.94 & 346.69 & 698.06 & 3258.63 & 1101.31 & 333.31 & 2665.63 & 500.69 & 839.25 & 525.63 \\
\hline Number of strokes & 22.81 & 24.25 & 22.50 & 22.50 & 22.00 & 24.44 & 20.44 & 22.63 & 21.44 & 22.44 \\
\hline $\begin{array}{l}\text { Relatedness with } \\
\text { prime }(1-7)\end{array}$ & 5.84 & 2.27 & 5.03 & 2.21 & 5.82 & 2.17 & 5.41 & 2.18 & 5.93 & 2.36 \\
\hline Isolated LDT RT (ms) & 565.50 & 566.69 & 580.71 & 577.66 & 554.41 & 541.18 & 544.20 & 549.90 & 549.26 & 553.05 \\
\hline
\end{tabular}

Note. Isolated LDT RT refers to the mean reaction times of target words in isolated lexical decision tasks

it is not yet postlexical, visual targets in the present study appeared on the computer screen 100 milliseconds before the offset of the auditory prime word and stayed on the screen for 750 milliseconds (Ahrens 2006) or until a response has been made. Participants' attention was focused on the middle of the screen by using a black mask, which allowed a small word-sized area $(4 \times 2.5 \mathrm{~cm})$ of the screen to be visible. For making lexical decisions, participants were instructed to always keep their hands on the two buttons of a response box, to press the right button (marked as 詞 ci2 'word') with their right hand if the target stimulus was a word, and to press the left button (marked as 非詞 feilci2 'non-word') with their left hand otherwise. The auditorily presented sentences continued to play after the visual targets appeared and after participants made the lexical decisions.

To familiarize participants with the task, 12 practice trials were given before the experimental trials. The 48 experimental trials were presented in random orders with an inter-trial interval of 2000 milliseconds. An internal CPU in the response box measured the time from the presentation of the visual target till a response was made on the button box or two seconds had passed, whichever was earlier. The measurements were accurate to the thousandths of a second, and were recorded to the nearest millisecond.

The whole experiment was divided into two blocks, each with 24 trials. To ensure that the participants paid attention to the auditorily presented sentences in addition to making lexical decisions, a questionnaire composed of 10 sentences, among which 5 appeared in the previous experimental block, was administered after each experimental block. Participants were asked to identify the sentences that they had just heard in the experiment. The entire experiment lasted about $30 \mathrm{~min}$.

\section{Results}

Priming effect was measured as the time taken to recognize a visual target that is semantically related to a particular meaning relative to a visual target that is semantically unrelated. If the RT of the semantically related word is significantly shorter than 
the RT of the semantically unrelated control, then this meaning of the prime word is considered activated.

Data from the 48 participants were analyzed. Errors (including incorrect and no responses), which accounted for less than $15 \%$ of the data points from each participant, were excluded from the RT analyses. All participants were able to correctly identify at least $80 \%$ of the sentences in the post-block sentence identification questionnaire. RTs above or below 2 standard deviations from the means across all conditions ( $2.08 \%$ of all data) were excluded from analyses.

The data were subjected to 2 (ROM: low versus high) $\times 2$ (contextual congruency: contextually supported meaning versus contextually unsupported meaning) $\times 2$ (target type: semantic associate versus control) analyses of variance (ANOVAs) with repeated measures, treating either the participants $\left(F_{1}\right)$ or the items $\left(F_{2}\right)$ as a random effect. A significant main effect of semantic priming was found $\left[F_{1}(1,47)=32.03, p<.001 ; F_{2}(1\right.$, $30)=35.76, p<.01]$, with the semantically related visual targets being recognized faster than the semantically unrelated control targets for both low-ROM and high-ROM words (see Figure 1). No other main effects or interactions were significant ( $p$ s > .05). This significant priming effect suggests that, regardless of the ROM of the ambiguous word and the existence of contextual support, both meanings of an ambiguous word were activated. RTs on the experimental and control conditions of the unambiguous primes were also compared. As expected, the priming effect was significant, with the semantically associated condition responded to faster than the control condition $\left[F_{1}\right.$ $\left.(1,47)=21.59, p<0.001 ; F_{2}(1,15)=12.84, p<0.01\right]$.

\section{Discussion}

Research on lexical ambiguity resolution during on-line sentence processing has been centered on when discourse information is used to select the contextually appropriate meaning of an ambiguous word. The modular perspective on lexical processing predicts automatic activations of word meanings independent of contextual influence at the initial stage of lexical access. The interactive perspective on lexical processing predicts early use of contextual information to selectively activate only the meaning that is

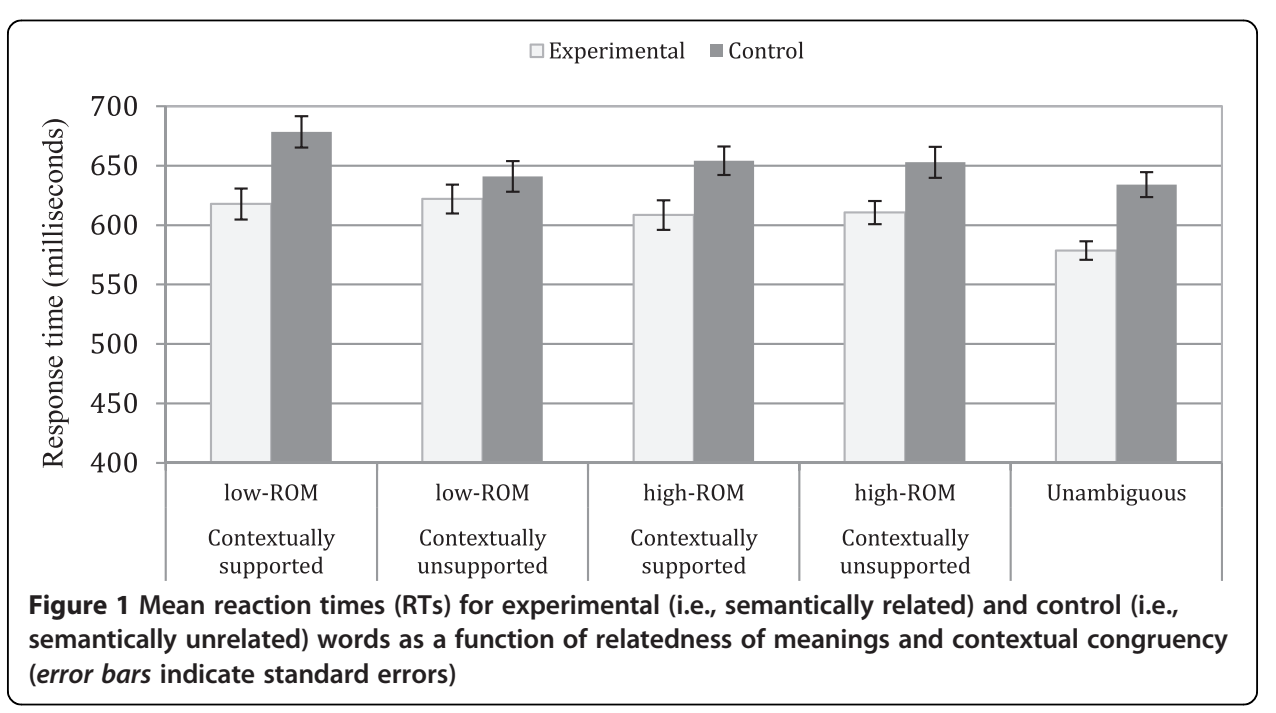


supported by the context. The present research revisits this debate by considering an additional factor-the relatedness among an ambiguous word's meanings. As words with closely related meanings present different processing patterns than words with unrelated meanings (e.g., isolated word recognition: Azuma and Van Orden 1997; Rodd et al. 2002; sentence comprehension: Frazier and Rayner 1990; Pickering and Frisson 2001), taking this additional factor into consideration offers us a clearer picture about the effect of context on lexical access.

The present study thus investigated the influence of context on the activation of meanings by contrasting words with different ROMs. Our cross-modal lexical priming experiment showed that, regardless of the ROM differences and contextual congruity, both meanings of an ambiguous word were activated at an early stage of lexical access. This finding is most compatible with the exhaustive semantic access account in lexical processing; namely, the processor activates a word's meanings exhaustively even when this meaning is not supported by the context. To our knowledge, this is the first study that specifically looked at the issue of contextual influence on lexical access at the two ends of the ROM continuum.

Considering the current findings along with those of previous studies summarized in Table 1, we now have a clearer picture about the semantic activation of ambiguous words in Mandarin Chinese sentences. Focusing on all the published findings at the onset or before the offset of the ambiguous primes, selective semantic activation has been observed on homophones that do not share orthography (Shu et al. 2000; Zhou et al. 2003), which violated the ORTHOGRAPHY-BASED SEMANTIC CO-ACTIVATION CONSTRAINT, and on homographs that involved different syntactic categories (Wu et al. 2002), which violated the SYNTACTICALLY LICENSED SEMANTIC CO-ACTIVATION CONSTRAINT. We therefore postulate these two constraints as the necessary conditions for semantic co-activation in Mandarin Chinese. The ORTHOGRAPHY-BASED SEMANTIC CO-ACTIVATION CONSTRAINT requires that co-activated meanings be associated with the same logographic representations, and the SYNTACTICALLY LICENSED SEMANTIC CO-ACTIVATION CONSTRAINT requires that coactivated meanings be of the same syntactic category so that they can be syntactically licensed in the same context. When the lexical ambiguity of a word satisfied these two constraints, exhaustive activation of lexical meanings can be observed (Ahrens 1998, 2001, the present study).

The present study extended this line of research by creating experimental materials that satisfied both the ORTHOGRAPHY CONSTRAINT and the SYNTACTIC CONSTRAINT, and examined whether the co-activation of word meanings may be modulated by different degrees of semantic relatedness between the associated meanings. We found that both meanings of an ambiguous word are activated regardless of the different ROMs. These results did not support the RELATEDNESS-TRIGGERED SEMANTIC CO-ACTIVATION HYPOTHESIS, according to which only the meanings that are closely-related should be co-activated. Our study suggested that the semantic relatedness between an ambiguous word's meanings does not modulate semantic coactivation. For both low-ROM and high-ROM words, the associated meanings are coactivated regardless of contextual congruency. This finding is compatible with Hino et al.'s (2010) proposal that the ROM of an ambiguous word may take effect only at a later decision-making stage of lexical processing. 
Recall that the ORTHOGRAPHY-BASED SEMANTIC CO-ACTIVATION CONSTRAINT in the present study focuses on the logographic orthography of Chinese. This constraint has important typological implications for the role that logographic orthography plays in the relation between lexical form and meaning. In lexical ambiguity resolution research, orthography has rarely been considered separately from phonology because most previous research investigated languages whose orthographies are sound-based. A Chinese study like ours offers a valuable opportunity to examine the distinctive effects of orthographic and phonological representations given that the logographic orthography of Chinese is not directly associated with phonology and can be taken as a distinct level of representation for Mandarin words. The literature on Chinese lexical ambiguity resolution suggests that Chinese logography provides an additional required condition for semantic co-activation.

For meanings associated with the same "lexical forms (broadly and ambiguously defined)" in Chinese, logographic, but not phonological, representations connect meanings that can be co-activated (Figure 2). Such a relation is distinct from the homophonic co-activation effects previously reported in English (e.g., Onifer and Swinney 1981; Seidenberg et al. 1982; Swinney 1979) and suggest that logographic languages like Chinese have an additional layer of orthographic representation that is consulted for semantic activation. From the perspective of how meanings are organized in the mental lexicon, meanings associated with the same phonological representations but differed on logographic representations (e.g., homophones like 裝 zhuang1 and 莊 zhuang1) may be stored under different lexical entries and are activated independently in Chinese. This constraint also implies that when a spoken word is heard, its logographic representation is automatically consulted and places a constraint on which meanings should be accessed.

For future studies, the ORTHOGRAPHY-BASED SEMANTIC CO-ACTIVATION CONSTRAINT can be recast as a hypothesis about the effect of orthography on semantic access. Languages such as English and Spanish whose orthographies differ on phonological transparency and consistency, and languages whose orthography is often associated with multiple pronunciations (e.g., Japanese kanjis and Mandarin 破音字 po4yin1zi4) will serve as ideal candidates for such investigations. Furthermore, the relatedness of meaning effect, which was not observed on words that share logographic forms in the present study, can be further investigated at the homophonic level. In sum, the role that orthography plays in accessing word meanings in sentential contexts should be further considered in future research for fine-tuning the relation between lexical access and discourse processing.

Before wrapping up, it is worth considering the role of syntactic information in semantic co-activation. The SYNTACTICALLY LICENSED SEMANTIC CO-ACTIVATION CONSTRAINT requires that co-activated meanings be syntactically licensed by the

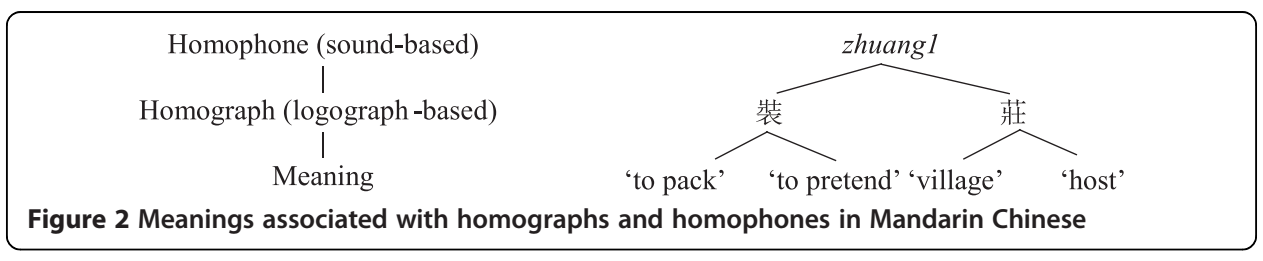


context. This constraint suggests that syntactic processing in the sentence precedes lexical access and can cast direct influence on which meanings should be activated. To control for the syntactic properties of the materials, we have focused on verbs in the present study. Given that verbs have been argued to be more susceptible to changing their meanings to fit a context than nouns (e.g., through semantic coercion: Ahrens 1996, Gentner and France 1988; Maratsos 1991; see also Pickering and Frisson 2001), whether the same co-activation effect can be observed on nouns and words of other syntactic categories should be further explored in future studies.

To sum up, the present study found that when lexical ambiguity is defined as meanings that share both orthographic and phonological lexical forms, these meanings can be coactivated regardless of contextual support as long as they are syntactically licensed by the sentential context. Taken together with previous results, these findings support the modular, syntax-first perspective about the relation between lexical and discourse processing. The syntactic parser analyzes the structure of the sentence and makes predictions about the syntactic category of an upcoming word. Meanings of different syntactic categories are accessed separately. Meanings of the same syntactic category are exhaustively activated regardless of contextual congruity. Lexical semantic processing and discourse processing are therefore initially independent of each other. Responding to the two research questions proposed in Section 4, then, we found that the multiple meanings of an ambiguous word are activated at the initial stage of lexical processing regardless of contextual compatibility. Context does not have an immediate effect on the activation of an ambiguous word's meanings. Furthermore, the relatedness between an ambiguous word's meanings does not have an effect on the activation of a particular word meaning.

As a final remark, the current findings are compatible with the exhaustive semantic access model and not with the ordered access model, which was supported by Frazier and Rayner's (1990) eye-tracking study. One possible reason for this discrepancy is that while the cross-modal lexical priming paradigm, as employed by the current study, displayed quick activations of all meanings associated with an ambiguous word during the initial stage of lexical processing, meanings of different frequencies may still induce differential processing costs at a later stage of lexical access, which the eye-tracking measures reveal. Future research can thus be devoted to untangling the temporal dimension of effects such as meaning frequency, ROM, and contextual congruency using different experimental paradigms.

\section{Conclusion}

The cross-modal lexical priming experiment reported in the current study suggested that the sentential context quickly sets up a syntactic frame for accessing words of a particular syntactic category. The meanings of an ambiguous word (i.e., homophonic homographs, which share both phonological and orthographic representations) are activated exhaustively as long as their syntactic category matches the expectation. Exhaustive semantic activation of a word was found on Mandarin words of varying ROMs suggesting that meanings associated with the same phonological and orthographic representations would be co-activated regardless of the degree of semantic relatedness between the meanings. These results support the modular, syntax-first theories for lexical and discourse processing. 


\section{Endnotes}

${ }^{a}$ Hino et al. (2013) further suggested that the logographic/alphabetic distinction may have led to a homophone disadvantage effect in an alphabetically scripted language but a homophone advantage effect in a logographically scripted language.

${ }^{\mathrm{b}}$ Given the phonological and orthographic variations across Chinese dialects, Table 1 focuses only on Mandarin studies. It therefore does not include a Cantonese study by Li and Yip (1996), which used as stimuli monosyllabic Cantonese nouns that share segmental representations but bear different tones and found contextual influence at the offset but not at the onset of the ambiguous words.

${ }^{\mathrm{C}}$ In Mandarin Chinese, 破音字 po4yin1zi4 or 多音字 duolyin1zi4 refers to homographs that share logographs but differ in pronunciation. As an example, the logograph 相, when appearing in words such as 相信 xiang1xin4 'to trust' and 相片 xiang4pian4 'photograph', is associated with two phonological representations-xiang1 and xiang4, respectively-which share the same segments but differ in tones. Such phonological variations associated with the same logographs are consequences of script changes (e.g., script simplification) through time. Since the potential effect of po4yin1zi4 is beyond the scope of the current study, the homographs that we use in the experiment reported below share both orthographic and phonological representations. We thank one of the reviewers for bringing up this relevant phenomenon though leave the effects associated with po4yin1zi4 for future studies.

${ }^{\mathrm{d}}$ In our reclassification of the materials of Ahrens (2001), we found 7 of the 16 experimental stimuli can be categorized as polysemous (having higher ROMs) and 9 can be categorized as homonymous (having lower ROMs).

\section{Additional file}

Additional file 1: Supporting information about the pretests and experimental materials is available online. (DOCX $229 \mathrm{~kb})$

Competing interests

The authors declare that they have no competing interests.

\section{Authors' contributions}

Both authors contributed to the research design, the planning of the experiment, and the statistical analyses. CCL supervised the running of the experiment, produced the theoretical interpretation of the results, and drafted the manuscript. YC created experimental stimuli, and ran the experiment and pretests. Both authors read and approved the final manuscript.

\section{Acknowledgements}

The authors would like to thank Kathleen Ahrens, Yung-O Biq, Hintat Cheung, Natsuko Tsujimura, the anonymous reviewers, and the Editor Chu-Ren Huang for helpful suggestions on previous versions of the manuscript. Any remaining errors are our own responsibility. This research was partially supported by a National Science Council of Taiwan Research Grant $(97-2410-\mathrm{H}-$ 003-044) and a research grant from the Faculty Research Support Program of Indiana University to the first author, Charles Lin.

\section{Author details \\ ${ }^{1}$ Department of East Asian Languages and Cultures, Indiana University, 355 North Jordan Avenue, Bloomington, IN 47405-1105, USA. ²Department of English, National Taiwan Normal University, Taipei, Taiwan.}

Received: 2 April 2015 Accepted: 8 August 2015

Published online: 06 November 2015

References

Ahrens, Kathleen. 1996. The mutability of noun and verb meaning. In Proceedings of the International Symposium on Chinese Languages and Linguistics, ed. Yuen-mei Yin, I-Li Yang, and Hui-Chen Chan, 335-371. Taipei: Academia Sinica.

Ahrens, Kathleen. 1998. Lexical ambiguity resolution: Languages, tasks, and timing. Syntax and Semantics 31: 11-31.

Ahrens, Kathleen. 2001. On-line sentence comprehension of ambiguous verbs in Mandarin. Journal of East Asian Linguistics 10: 337-358. 
Ahrens, Kathleen. 2006. The effect of visual target presentation times on lexical ambiguity resolution. Language and Linguistics 7: 677-696.

Allan, Keith. 1986. Linguistic meaning, vol. 1. London: Routledge and Kegan Paul.

Azuma, Tamiko, and Guy C Van Orden. 1997. Why safe is better than fast: The relatedness of a word's meanings affects lexical decision times. Journal of Memory and Language 36: 484-504.

Beretta, Allen, Robert Fiorentino, and David Poeppel. 2005. The effects of homonymy and polysemy on lexical access: An MEG study. Cognitive Brain Research 24: 57-65.

Borowsky, Ron, and Michael E J Masson. 1996. Semantic ambiquity effects in word identification. Journal of Experimental Psychology: Learning, Memory, and Cognition 22: 63-85.

Chen, Keh-jiann, Chu-Ren Huang, Li-ping Chang, and Hui-Li Hsu. 1996. Sinica corpus: Design methodology for balanced corpora. In Proceeding of the 11th Pacific Asia Conference on Language, Information and Computation, ed. Byung-Soo Park and Jong-Bok Kim, 167-176. Seoul: Kyung Hee University.

Conrad, Carol. 1974. Context effects in sentence comprehension: A study of the subjective lexicon. Memory and Cognition 2: 130-138.

Cruse, DA. 1986. Lexical semantics. Cambridge, UK: Cambridge University Press.

Durkin, Kevin, and Jocelyn Manning. 1989. Polysemy and the subjective lexicon: Semantic relatedness and the salience of intraword senses. Journal of Psycholinguistic Research 18: 577-612.

Ferreira, Fernanda, and Charles Clifton. 1986. The independence of syntactic processing. Journal of Memory and Language 25: $348-368$.

Fodor, Jerry. 1983. The modularity of mind: An essay on faculty psychology. Cambridge, MA: MIT Press.

Forster, Kenneth I. 1979. Levels of processing and the structure of the language processor. In Sentence processing: Psycholinguistic essays presented to Merrill Garrett, ed. William E Cooper and Edward Walker, 27-84. Hillsdale, N.J.: Erlbaum.

Forster, Kenneth I, and Elizabeth S Bednall. 1976. Terminating and exhaustive search in lexical access. Memory and Cognition 4: 53-61.

Frazier, Lyn. 1987. Sentence processing: A tutorial review. In Attention and performance, vol. XII: The psychology of reading, ed. Max Colheart, 601-681. Hillsdale, NJ: Earlbaum.

Frazier, Lyn, and Janet Dean Fodor. 1978. The sausage machine: A new two-stage parsing model. Cognition 6: 291-325.

Frazier, Lyn, and Keith Rayner. 1990. Taking on semantic commitments: Processing multiple meanings vs. multiple senses. Journal of Memory and Language 29: 181-200.

Friederici, Angela D. 2002. Towards a neural basis of auditory sentence processing. Trends in Cognitive Science 6: 78-84.

Friederici, Angela D, and Jürgen Weissenborn. 2007. Mapping sentence form onto meaning: The syntax-semantic interface. Brain Research 1146: 50-58.

Gentner, Dedre, and Ilene M France. 1988. The verb mutability effect: Studies of the combinatorial semantics of nouns and verbs. In Lexical ambiguity resolution: Perspectives from psycholinguistics, neuropsychology, and artificial intelligence, ed. Steven L Small, Garrison W Cottrell, and Michael K Tanenhaus, 343-382. San Mateo, CA: Kaufmann.

Glucksberg, Sam, Roger J Kreuz, and Susan H Rho. 1986. Context can constrain lexical access: Implications for models of language comprehension. Journal of Experimental Psychology: Learning, Memory, and Cognition 12: 323-335.

Guo, Jia, Hua Shu, and Ping Li. 2007. Context effects in lexical ambiguity processing in Chinese: A meta-analysis. Journal of Cognitive Science 8: 91-107.

Hino, Yasushi, and Stephen J Lupker. 1996. Effects of polysemy in lexical decision and naming: An alternative to lexical access accounts. Journal of Experimental Psychology: Human Perception and Performance 22: 1331-1356.

Hino, Yasushi, Penny M Pexman, and Stephen J Lupker. 2006. Ambiguity and relatedness effects in semantic tasks: Are they due to semantic coding? Journal of Memory and Language 55: 247-273.

Hino, Yasushi, Yuu Kusunose, and Stephen J Lupker. 2010. The relatedness-of-meaning effect for ambiguous words in lexical-decision tasks: When does relatedness matter? Canadian Journal of Experimental Psychology 64: 180-196.

Hino, Yasushi, Yuu Kusunose, Stephen J Lupker, and Debra Jared. 2013. The processing advantage and disadvantage for homophones in lexical decision tasks. Journal of Experimental Psychology: Learning, Memory, and Cognition 39: $529-551$

Hogaboam, Thomas W, and Charles A Perfetti. 1975. Lexical ambiguity and sentence comprehension. Journal of Verbal Learning and Verbal Behavior 14: 265-274.

Huang, Chu-Ren, Shu-Kai Hsieh, Jia-Fei Hong, Yun-Zhu Chen, I Su, Yong-Xiang Chen, and Sheng-Wei Huang. 2010. Chinese Wordnet: Design, implementation, and application of an infrastructure for cross-lingual knowledge processing. Journal of Chinese Information Processing 24: 14-23.

Huang, Chu-Ren, and Nianwen Xue. 2015. Chinese lexical semantics: From radicals to event structure. In The Oxford handbook of Chinese linquistics, ed. William S-Y. Wang, and Chaofen Sun, 290-305. Oxford, UK: Oxford University Press.

Jastrzembski, James E. 1981. Multiple meanings, number of related meanings, frequency of occurrence, and the lexicon Cognitive Psychology 13: 278-305.

Jastrzembski, James E, and Robert F Stanners. 1975. Multiple word meanings and lexical search speed. Journal of Verbal Learning and Verbal Behavior 14: 534-537.

Kellas, George, F Richard Ferraro, and Greg B Simpson. 1988. Lexical ambiguity and the timecourse of attentional allocation in word recognition. Journal of Experimental Psychology: Human Perception and Performance 14: 601-609.

Kintsch, Walter, and Ernest F Mross. 1985. Context effects in word identification. Journal of Memory and Language 24: $336-349$

Klein, Devorah E, and Gregory L Murphy. 2001. The representation of polysemous words. Journal of Memory and Language 45: 259-282.

Klein, Devorah E, and Gregory L Murphy. 2002. Paper has been my ruin: Conceptual relations of polysemous senses. Journal of Memory and Language 47: 548-570. 
Klepousniotou, Ekaterini, and Shari R Baum. 2007. Disambiguating the ambiguity advantage effect in word recognition: An advantage for polysemous but not homonymous words. Journal of Neurolinguistics 20: 1-24.

Klepousniotou, Ekaterini, Bruce G Pike, Karsten Steinhauer, and Vincent Gracco. 2012. Not all ambiguous words are created equal: An EEG investigation of homonymy and polysemy. Brain and Language 123: 11-21

Li, Ping. 1998. Crosslinguistic variation and sentence processing: The case of Chinese. Syntax and Semantics 31: 33-53.

Li, Ping, and Michael C Yip. 1996. Lexical ambiguity and context effects in spoken word recognition: Evidence from Chinese. In Proceedings of the 18th Annual Conference of the Cognitive Science Society, ed. Garrison Cottrell, 228-232. Hillsdale: Lawrence Erlbaum Associates.

Li, Ping, and Michael C Yip. 1998. Context effects and the processing of spoken homophones. Reading and Writing 10: 223-243.

Li, Ping, Hua Shu, Michael C Yip, Yaxu Zhang, and Yinghong Tang. 2001. Lexical ambiguity in sentence processing: Evidence from Chinese. In Sentence processing in East Asian languages, ed. Mineharu Nakayama, 111-129. Stanford, CA: Center for the Study of Language and Information Publications.

Lin, Chien-Jer Charles, and Kathleen Ahrens. 2010. Ambiguity advantage revisited: Two meanings are better than one when accessing Chinese nouns. Journal of Psycholinguistic Research 39: 1-19.

Locker, Lawrence, Greg B Simpson, and Mark Yates. 2003. Semantic neighborhood effects on the recognition of ambiguous words. Memory and Cognition 31: 505-515.

Lucas, Margery. 1987. Frequency effects on the processing of ambiguous words in sentence contexts. Language and Speech 30: 25-46.

Lucas, Margery. 1999. Context effects in lexical access: A meta-analysis. Memory and Cognition 27: 385-398.

Lupker, Stephen J. 2007. Representation and processing of lexically ambiguous words. In The Oxford handbook of psycholinguistics, ed. M Gareth Gaskell, 159-174. Oxford, UK: Oxford University Press.

Lyons, John. 1995. Linguistic semantics: An introduction. Cambridge, UK: Cambridge University Press.

Maratsos, Michael P. 1991. How the acquisition of nouns may be different from that of verbs. In Biological and behavioral determinants of language development, ed. Norman A Krasnegor, Duane M Rumbaugh, Richard L Schiefelbusch, and Michael Studdert-Kennedy, 67-88. Hillsdale, NJ: Lawrence Erlbaum.

Marslen-Wilson, William, and Lorraine Komisarjevsky Tyler. 1980. The temporal structure of spoken language understanding. Cognition 8: 1-71.

McClelland, James L, and Jeffrey L Elman. 1986. The trace model of speech perception. Cognitive Psychology 18: 1-86.

McElree, Brian, and Teresa Griffith. 1998. Structural and lexical constraints on filling gaps during sentence processing: A time-course analysis. Journal of Experimental Psychology: Learning, Memory, and Cognition 24: 432-460.

Millis, Michelle L, and Scott B Button. 1989. The effect of polysemy on lexical decision time: Now you see it, now you don't. Memory and Cognition 17: 141-147.

Ministry of Education revised Chinese dictionary 教育部重編國語辭典修訂本. 1994. Taipei: Ministry of Education, Republic of China. http://dict.revised.moe.edu.tw/. Accessed 1 August 2008.

Oden, Gregg C, and James L Spira. 1983. Influence of context on the activation and selection of ambiguous word senses. The Quarterly Journal of Experimental Psychology 35: 51-64.

Onifer, William, and David A Swinney. 1981. Accessing lexical ambiguities during sentence comprehension: Effects of frequency of meaning and contextual bias. Memory and Cognition 9: 225-236.

Palmer, Frank Robert. 1981. Semantics, 2nd ed. Cambridge, UK: Cambridge University Press.

Paul, Stephen T, George Kellas, Nichael Martin, and Matthew B Clark. 1992. Influence of contextual features on the activation of ambiguous word meanings. Journal of Experimental Psychology: Learning, Memory, and Cognition 18: 703.

Pickering, Martin J, and Steven Frisson. 2001. Processing ambiguous verbs: Evidence from eye movements. Journal of Experimental Psychology: Learning, Memory, and Cognition 27: 556-573.

Pylkkänen, Liina, Rodolfo Llinás, and Gregory L Murphy. 2006. The representation of polysemy: MEG evidence. Journal of Cognitive Neuroscience 18: 97-109.

Rodd, Jennifer, Gareth Gaskell, and William Marslen-Wilson. 2002. Making sense of semantic ambiguity: Semantic competition in lexical access. Journal of Memory and Language 46: 245-266.

Rubenstein, Herbert, Lonnie Garfield, and Jane A Millikan. 1970. Homographic entries in the internal lexicon. Journal of Verbal Learning and Verbal Behavior 9: 487-494.

Seidenberg, Mark S, Michael K Tanenhaus, James M Leiman, and Marie Bienkowski. 1982. Automatic access of the meanings of ambiguous words in context: Some limitations of knowledge-based processing. Cognitive Psychology 14: 489-537.

Shu, Hua, Yinghong Tang, and Yaxu Zhang 舒华, 唐映紅, 張亞旭. 2000. A study on the resolution of lexical ambiguity of two-syllable homophones in Chinese 汉语双音节同音词词汇歧义消解过程的研究. Acta Psychologica Sinica 心理学报 32: 247-252.

Simpson, Greg B. 1981. Meaning dominance and semantic context in the processing of lexical ambiguity. Journal of Verbal Learning and Verbal Behavior 20: 120-136.

Simpson, Greg B, and Curt Burgess. 1985. Activation and selection processes in the recognition of ambiguous words. Journal of Experimental Psychology: Human Perception and Performance 11: 28-39.

Simpson, Greg B, and Merilee A Krueger. 1991. Selective access of homograph meanings in sentence context. Journal of Memory and Language 30: 627-643.

Sproat, Richard. 2000. A computational theory of writing systems. Cambridge, UK: Cambridge University Press.

Swinney, David A. 1979. Lexical access during sentence comprehension: (Re)consideration of context effects. Journal of Verbal Learning and Verbal Behavior 18: 645-659.

Swinney, David A, and Tracy Love. 1996. Coreference processing and levels of analysis in object-relative constructions: Demonstration of antecedent reactivation with the cross-modal priming paradigm. Journal of Psycholinguistic Research 25: 5-24.

Tabossi, Patrizia. 1988. Accessing lexical ambiguity in different types of sentential contexts. Journal of Memory and Language 27: 324-340.

Tabossi, Patrizia, and Francesco Zardon. 1993. Processing ambiguous words in context. Journal of Memory and Language 32: 359-372. 
Tabossi, Patrizia, Lucia Colombo, and Remo Job. 1987. Accessing lexical ambiguity: Effects of context and dominance. Psychological Research 49: 161-167.

Tanenhaus, Michael K, James M Leiman, and Mark S Seidenberg. 1979. Evidence for multiple stages in the processing of ambiguous words in syntactic contexts. Journal of Verbal Learning and Verbal Behavior 18: 427-440.

Till, Robert E, Ernest F Mross, and Walter Kintsch. 1988. Time course of priming for associate and inference words in a discourse context. Memory and Cognition 16: 283-298.

Vu, Hoang, George Kellas, and Stephen T Paul. 1998. Sources of sentence constraint on lexical ambiguity resolution. Memory and Cognition 26: 979-1001.

Vu, Hoang, George Kellas, Kimberly Metcalf, and Ruth Herman. 2000. The influence of global discourse on lexical ambiguity resolution. Memory and Cognition 28: 236-252.

Williams, John N. 1992. Processing polysemous words in context: Evidence for interrelated meanings. Journal of Psycholinguistic Research 21: 193-218.

Wu, Ningning, and Hua Shu 武宁宁, 舒华. 2002. Meaning activation of Chinese syntactic category ambiguous words in sentence context 句子语境中汉语词类歧义词的意义激活. Acta Psychologica Sinica 心理学报 34: 454-461.

Zhang, Yaxu, Ningning Wu, and Michael Yip. 2006. Lexical ambiguity resolution in Chinese sentence processing. In Handbook of East Asian psycholinguistics vol. 1, Chinese, ed. Ping Li, Li Hai Tan, Elizabeth Bates, and Ovid J L Tzeng, 268-278. Cambrdige, UK: Cambridge University Press.

Zhou, Xiaolin, and William Marslen-Wilson. 2000. The relative time course of semantic and phonological activation in reading Chinese. Journal of Experimental Psychology: Learning, Memory, and Cognition 26: 1245-1265.

Zhou, Zhijin, Yongming Chen, Lixia Yang, and Hsuan-Chih Chen 周治金, 陈永明, 杨丽霞, 陈烜之. 2003. The inhibition mechanism for resolving lexical ambiguity of two-syllable homophones in Chinese 汉语同音歧义词歧义消解的 过程及其抑制机制. Acta Psychologica Sinica 心理学报 35: 1-8.

\section{Submit your manuscript to a SpringerOpen ${ }^{\circ}$} journal and benefit from:

- Convenient online submission

- Rigorous peer review

- Immediate publication on acceptance

- Open access: articles freely available online

- High visibility within the field

- Retaining the copyright to your article 